\title{
40
}

\section{AN ALTERNATIVE INTERFACE FOR MULTIMEDIA SERVICE STATIONS}

\author{
Marizete S. Santos, Fernando da F. de Souza and Ana C. Salgado \\ Universidade Federal de Pernambuco, Dept $^{\circ}$ de Informática \\ Cidade Universitária, CEP 50740-540, Recife - PE - Brasil \\ E-mail: \{mss,fdfd,acs\}@di.ufpe.br \\ Fax number: + 55(81)2714925
}

\begin{abstract}
KEY WORDS: Multimedia station, Interface, Presence Sensors
ABSTRACT: This work introduces a new resource for public multimedia service stations a presence sensor. This device permits the computer to detect the presence of a user, so that the user does not need to initiate the interaction process with the computer. Studies done with a variety of users prove that this new resource, in addition to facilitating the initial contact with the computer, also improves the human-machine interaction, once the user loses the initial inhibition to begin communication. The project proposes the implementation of a multimedia station that combines various existing multimedia resources in conventional stations with the presence sensor.
\end{abstract}

\section{INTRODUCTION}

The human being is in constant evolution which can be verified by looking at the history of humanity. The human race is always looking for new discoveries to complete his knowledge. One example of this evolution is the discovery of the computer, a machine that can be used for the transmission and manipulation of information. Certainly, the computer represents one of the greatest advances of humanity in the technological field.

Another advance in humanity has its beginning now, at the conclusion of this century, with the so-called digital multimedia, an area of Computer Science that links various types of information, treating them in a dynamic and integrated manner. According to (Soares et al., 1992), the term multimedia is used to classify applications that combine various types of media such as text, graphics, sound, and static and moving images. Given the great technological advances in this field it is actually possible to join a number of these media resources into one multimedia station for a variety of public services.
Despite this technological advance in which public service terminals possess the most diversified resources, such as touch-sensitive screens, CD-ROMs, sound boards, speakers, etc., many of today's stations are still in need of a better method for interacting with the user.

Great efforts have been dedicated for the purpose of constructing interfaces that are interactive and user-friendly (Brad, 1994; Shneiderman, 1987; Sommerville, 1992).

With these objectives in mind, this work proposes the use of a resource which is seen as 'an alternative interface for multimedia service stations.' This resource eases the first step in the human-machine interaction, freeing the user from having to initiate the interaction which normally involves some previous knowledge.

The general idea is to combine the use of a presence sensor in multimedia service stations with the other resources already implemented on the existing conventional stations. A brief description of the station is presented in the following section. 


\section{STATION PROPOSAL}

The features of the multimedia service station such as its ergonomic and innovative design, the presence sensor, a touch-sensitive screen in addition to sound and image capabilities are described in the following sections.

\subsection{Design}

In the designing phase of the station, the ergonomic recommendations and the aesthetics of the product are taken into consideration.

(Ilida, 1992) states that the security, well-being and comfort of the user are the practical objectives of Ergonomics. The issue of comfort is considered not only in the physical shape of the product, but it is also considered in the software development process of the system. Various aspects are analyzed in order to attain this objective. This research emphasizes Ergonomy, justifiably, because it plans to arrive at a design which is comfortable, safe, friendly and most natural to the user.

To accomplish these goals, ergonomists study various aspects of human behavior, making use of anthropometric, physiological, psychological and social knowledge of humans.

Involved in this research, we are thoroughly reviewing and critiquing the aesthetics of the present designs. Our design in development goes beyond the conventional existing versions. A traditional preference is not imposed. Instead, what is adopted, is the most user-friendly and agreeable shape possible in order to attract the user.

\subsection{The Presence Sensor}

The presence sensor's principal function is to immediately recognize the presence of the user. In this way, the user does not have to make any initial actions to instigate interaction with the computer. This is explained in more detail in section 3 .

\subsection{The Screen}

Now we discuss the addition of a touch-sensitive screen to the station. This feature will provide an "intelligent keyboard" which reconfigures instantaneously whenever necessary during the process of communication. The principal objective is to provide the most agreeable interface, eliminating unnecessary keys. Furthermore, the user will be spared from typing so many words or numbers.

\subsection{Sound}

In this area, studies are presently being conducted on the use of sound files and images. Again, the objective is to supply an even more agreeable communication between the user and the machine. Here, the sound file types are WAVE and MIDI. (Wodaski, 1993)

The features described above are combined in such a way as to diminish as much as possible, the number of operations that the user must execute. Thus, liberating the user from performing inhibiting tasks or ones that are not directly related to the principal objectives at hand.

\section{THE PRESENCE SENSOR - AN ALTERNATIVE INTERFACE}

\subsection{Description}

The presence sensor is a data entry device whose main function is to immediately detect a user's presence and then to initiate the program on the video monitor. As soon as the communication is established, interaction with the computer begins. The utilization of the presence sensor (with the station) makes the communication more simple and natural, once the user loses his/her inhibition, thus, easing the interaction with the machine.

\subsection{Existing Types}

There exist several types of sensors that can be coupled with stations, each of which functions in a slightly different manner. Three types are listed below:

- Infra-red Reflection Sensors (Neubert, 1975)

- Ultrasonic Sensors (Hueter, 1985)

- Pressure (Weight) Sensors.

Despite the fact that various types of sensors are in existence, we implement, in this work, a pressure sensor mainly because of its low cost and simple construction.

\subsection{Project And Operation}

The operation of the presence sensor is represented in Fig. 1.

Normally, the switch is deactivated. When the user nears the station, his/her weight activates the switch, generating a signal which is treated by the next module in Fig. 1 (Filter). This block functions as a type of filter, so that upon receiving a signal, it appropriately distinguishes between a true signal and any external interferences that cause 
fluctuations which may inadvertently activate the system.

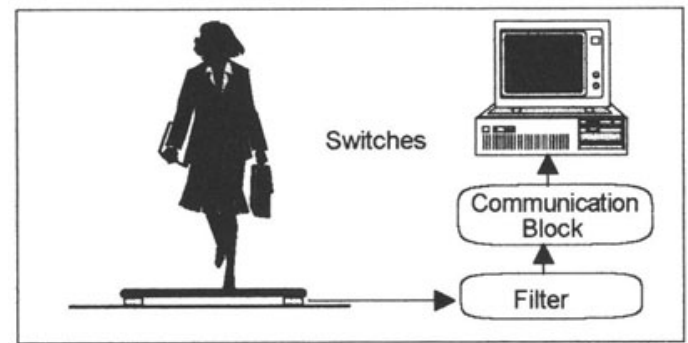

Figure 1: Flow Chart of the Presence Sensor's Operation Switches

At the electrical level, the sensor functions by means of a circuit (Fig. 2) that is part of the TTL family (transistor-transistor logical). This circuit is fed by the computer's own power supply.

External factors can cause interference in the switch. So, it is of utmost importance that a capacitor be present in order to avoid voltage fluctuations that go directly to the computer.

After the switch is closed, the capacitor weakens the fluctuation until the voltage stabilizes. The double logical invertor transmits this stable voltage, which the logical level 1 , to the serial port of the computer.

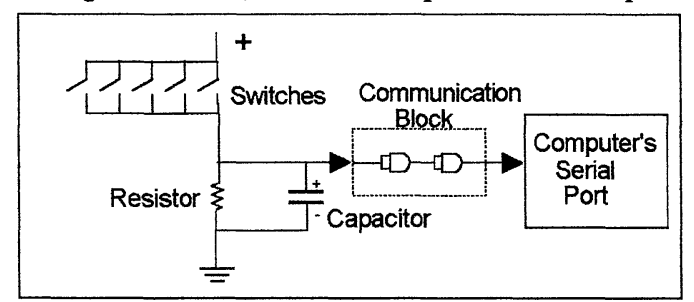

Figure 2: Electric Diagram of the Presence Sensor. Switches

\subsection{Tests Peformed}

In order to prove the hypothesis that the presence sensor truly improves the human-machine interaction, three public demonstrations of the presence sensor were performed, followed by the completion of research/survey questionnaires by users of various ages and professional activities.
The research studies can be divided into two groups: experimental and descriptive. The descriptive study, which consists of making observations and inquiries, was adopted in this case. The inquiry consists of an interview, verbalizations and administering a questionnaire. Among the various types of existing interviews, preference was given here to the semi-structured interview. This consists of a small number of open questions.

The first presentation of the presence sensor occurred during the IX School of Computation ${ }^{1}$ in July 1994 . The second presentation of the presence sensor was given during the inauguration of an interactive science museum ${ }^{2}$ in September 1994, and the third presentation took place at the 3rd Northeast Conference of Computer Science and Telecommunications, and at the 3rd Northeast Computer Science Fair ${ }^{3}$ in October 1994. The three events took place in Recife, Brazil.

In the first presentation, the presence sensor was totally visible to the user and there were no other features present inviting the user to use the system. After the user exerted pressure on the sensor, the program was activated on the screen. In the second and third presentations, the sensor was no longer visible to the user. It was observed that children were very motivated to use the computer several times and the adults, in general, also felt encouraged to use it. An audio and graphic display were also utilized in order to attract attention. Here, it was noted that the sytem was well accepted by the users who did not feel inhibited while in front of the computer.

The programming language utilized for the construction of the test programs for the three presentations was the authoring language HSC InterActive. During the programming phase, it was observed that this language is slightly limited, in spite of its acceptance of sound and image files. It is not adequate for the implementation of applications which utilize other resources such as presence sensors, for example.

\footnotetext{
$1 \quad$ The Computation School is an event that occurs every two years at Brazilian universities, where professors, students, nationaland international researchers and company representatives meet to discuss subjects related to Computer Science.

2 The interactive science museum is a project developed by the Secretary of Science and Technology of the the Governor of the Stat of Pernambuco, whose goal is to offer a technological museum to primary and secondary schools, where the students and teachers may utilize many technological resources that are not available in their schools.

3 The Northeast Conference of Computer Science and Telecommunications is an event occurring annually which attracts users, researchers, business representatives in the area of computers. The Computer Science Fair takes place annually along with the forementioned Conference. In this fair, novelties in the area of tools, software and hardware are displayed.
} 


\subsection{Survey Results}

The questionnaires were completed by 102 randomily chosen users from the three public presentations.

For the first question, $100 \%$ of those surveyed affirmed that they did not encounter any initial difficulties in interacting with the station.

The second question offered three options for which the person questioned could classify the system easy, difficult or regular. Again, $100 \%$ affirmed that the system was easy to use.

A comparison of the multimedia service station to other multimedia stations was made in the third question. $70.59 \%$ of those questioned pointed out that the presence sensor was the principle advantage over the other systems. $19.61 \%$ responded that they had not had any prior experiences with multimedia stations to make a comparison. $9.8 \%$ indicated the software used was disadvantage for the test.

In the fourth question, it was inquired if the user perceived the presence of the sensor; $50 \%$ of those surveyed perceived the presence of the sensor. Of these $19.61 \%$ were afraid of breaking it due to their own weight, $10.78 \%$ were apprehensive about stepping on it and $19.61 \%$ liked the sensation of stepping on the sensor.

The fifth question called for suggestions on how to improve the system; $40.20 \%$ did not suggest any improvement, $25.49 \%$ suggested improvements in relation to the software used and $34.31 \%$ suggested that the user should not be capable of perceiving the existence of the sensor on which they will step.

\section{CONCLUSIONS}

This research presented a proposal on using a presence sensor for the purpose of improving the initial communication with the computer. This idea of using a presence sensor arose from the necessity of finding a form of initial communication that would stop the intimidation and apprehension that many novice users experience due to their feelings of inadequacy in using a computer.

The survey results proved that the presence sensor, acting as the initial means of communication, has a fundamental importance in the communication process with the machine. This initial contact is the principal obstacle to be overcome in the use of multimedia public service stations.

The survey study also revealed the great importance of camouflaging the sensor so that it will not be visible to the user.

The software that was developed for these 3 presentations focused primarily on the initial human-computer interaction. However, now considering suggestions made by those interviewed, we intend to initiate software improvements that will not be limited to the initial interaction.

Finally, it was determined that the use of a feature, such as the presence sensor, in multimedia stations, was seen to facilitate the first step in the human-machine interaction, in a way that freed the user from having to initiate the communication process, giving great importance to the improvement of the human-machine interaction.

\section{REFERENCES}

Brad, A. M. (1994). Challenges of $\mathrm{HCI}$ Design and Implementation. Interactions, 1(1), 73-82.

Cushman, W. H. (1991). Human factors in product design. New York: Elsévier.

Hueter, T. F. (1955). Sonics: techniques for the Use of sound and ultrasound in engineering and science. New York: J. Wiley G. Sons.

Ilida, I. (1990). Ergonomia: Projeto e producão. São Paulo: Edgard Blucher.

Neubert, H. K. P. (1975). Instrument transducers. Oxford: Clarendon Press.

Shneiderman, B (1987). Designing the user interface: strategies for effective human-computer interaction. Massachusets: Addison-Wesley.

Soares, L. F. G., Tucherman, L., Casanova, M. A. \& Nunes, P. R. L. (1992). Fundamentos de sistemas multimídia. Porto Alegre: Instituto de Informática da UFGRS.

Sommerville, I. (1992). Software engineering. New York: Addison-Wesley.

Wodaski, R. (1993). Multimídia. Rio de Janeiro: Ciência Moderna. 